\title{
L-Sensors in Aerospace
}

\author{
Sabzpoushan $\mathrm{SH}^{1}$ and Sabzpoushan SA ${ }^{2}$ \\ ${ }^{1}$ Biomedical Engineering Department, School of Electrical Engineering, Iran University of Science and Technology (IUST), Iran \\ ${ }^{2}$ Department of Aerospace Engineering, Sharif University of Technology, Tehran, Iran
}

"Corresponding author: Sabzpoushan SH, Biomedical Engineering Department, School of Electrical Engineering, Iran University of Science and Technology (IUST), Iran, Tel: +98-21-73225729,73225600; E-mail: sabzposh@iust.ac.ir

Received date: Feb 28 2014, Accepted date: Feb 28 2014, Published date: Mar 252014

Copyright: () 2014 Sabzpoushan. This is an open-access article distributed under the terms of the Creative Commons Attribution License, which permits unrestricted use, distribution, and reproduction in any medium, provided the original author and source are credited.

\section{Editorial}

Recently I postulated a new concept in the field of sensors; Lsensors. With the L-sensor I mean a living sensor. As a good and practical proposal for L-sensor I can name a neuron.

Neuron In simple terms, is a cell specialized to generate and conduct electrical impulses and to carry information from one part of the body to another. Thanks to their numerous branch-like processes, neurons interconnect forming a massive network of "wires" that extend throughout the body. By sending messages across this network, the different parts of the human body interact and communicate with each other. Every time we move, think, remember something or feel, our neurons are at work.

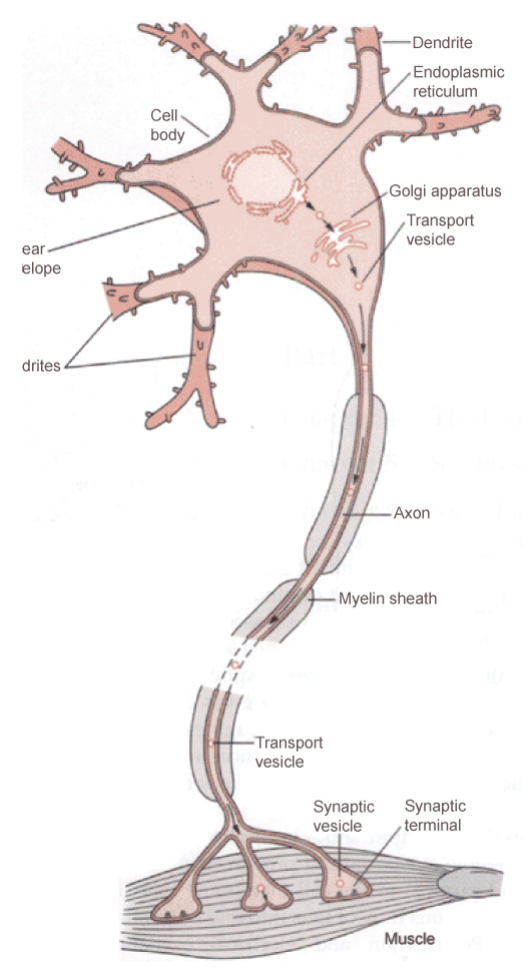

Figure 1: Shows a typical neuron of human nervous system

In our body, sensory neurons carry signals from the outer parts into the central nervous system or CNS, the speed of signal transmission in neurons is said to be about $7000 \mathrm{~m} / \mathrm{sec}$.
It is estimated that human brain contains about 1011 neurons that are interconnected via a complex network. This huge number of elements and complex interconnections among them forms the most robust, fastest and lightest weight known control system.

Considering light weight, fast and robust action of such nervous system, why don't we use it in an aircraft or spacecraft? (Figures1, 2)

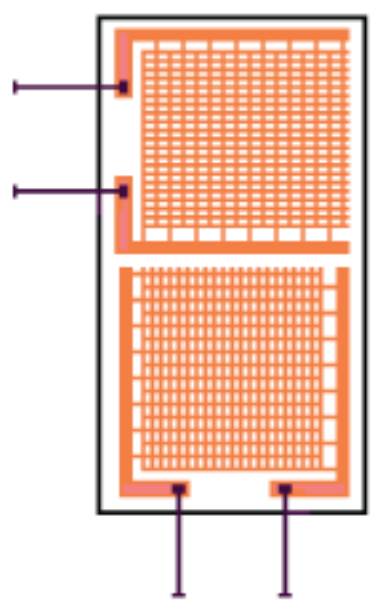

Figure 2: Depicts a sensor array inspired neural networks which is used in advanced aircrafts.

Efforts are currently underway to work with different conceptual types of distributed embedded sensor architectures to develop biologically inspired sensory system for aerospace vehicles. Some authors have reported works investigating the ability of living neurons to act as a set of neuronal weights which were used to control the flight of a simulated aircraft. These weights were manipulated via high frequency stimulation inputs to produce a system in which a living neuronal network would "learn" to control an aircraft for straight and level flight.

At NASA, researches are currently in progress to work with different conceptual types of distributed embedded sensor architectures to develop a biologically inspired sensory system for aerospace vehicles.

In other studies signal processing algorithms and bio-like distributed sensor network systems are used on large structures and integrated aerospace vehicles for acoustic emission wave source localization and preliminary results are presented. These systems allow for a great reduction in the amount of data that needs to be processed and also reduce the chances of false alarms from ambient noises. 
Citation: Sabzpoushan SH, Sabzpoushan SA (2014) L-Sensors in Aerospace. Sensor Netw Data Commun 3: e101. doi: 10.4303/2090-4886.1000e101

Page 2 of 2

Concerning above efforts and in connection with light weight, selves that future aerospace vehicles will apply live distributed robustness and fast speed of real neural networks we may satisfy our embedded sensor arrays mimicking human neural system. 